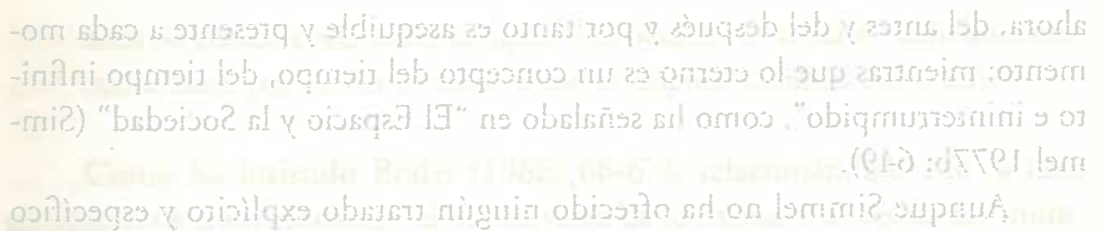

\title{
SIMMEL: LA MODA, EL ATRACTIVO FORMAL DEL LÍMITE
}

JORGE LOZANO

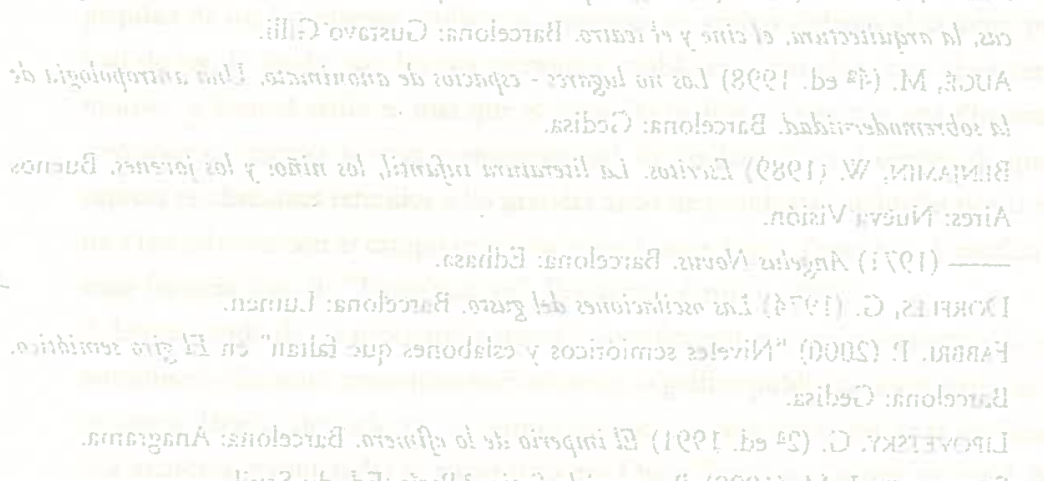

MODA: Madama Morte, madama Morte [...] Io sono la Moda. Mia sorella.

MORTE: Mia sorella?

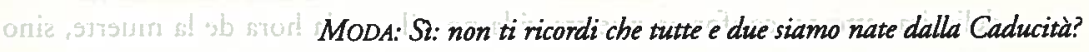
G. LEOPARDI, Dialogo della moda e della morte

En carta a Walter Benjamin desde Nueva York el 10 de noviembre de 1938, Adorno le comenta la opinión que le merece el "Baudelaire" como modelo de los. Passagen, advirtiéndole severamente que "la determinación materialista de los caracteres culturales es posible sólo con la mediación del proceso global". Adorno le reprocha lo mismo que a Simmel: "no en vano cita usted a Simmel", a quien lanza una mirada de hastío, dirá Benjamin en su respuesta, esto es, la falta de concreción histórica que reduce el ejemplo a la esfera de lo eterno. 1

He aquí una de las recurrentes críticas a nuestro autor, del que hay que decir, sin embargo, como ha sostenido Frisby (1985), ${ }^{2}$ que las instantáneas de la realidad social de Simmel son coherentemente consideradas sub specie aeternitatis.

Baste recordar que para Simmel (Rembrandt) "cada momento singular de la vida es la totalidad de la vida"; o "lo intemporal es independiente del 
ahora, del antes y del después y por tanto es asequible y presente a cada momento; mientras que lo eterno es un concepto del tiempo, del tiempo infinito e ininterrumpido", como ha señalado en "El Espacio y la Sociedad" (Simmel 1977b: 649).

Aunque Simmel no ha ofrecido ningún tratado explícito y específico sobre la temporalidad, ${ }^{3}$ sí afronta la distinción entre temporal y atemporal, donde el presente es un concepto límite "que no va más allá de la absoluta inextensión del momento"; el presente indica simplemente el punto de encuentro entre pasado y futuro, pero como el pasado ya no es y el futuro todavía no es, sólo es real el presente, algo que es lógicamente atemporal. El tiempo, gustaba de decir, no está en la realidad y la realidad no es tiempo.

En su breve ensayo "Para una metafisica de la muerte" encontramos preciosas consideraciones sobre esto mismo. Alli dice:

El misterio de la forma reside en el hecho de que es frontera; es la cosa misma y al mismo tiempo el finalizar de la cosa, la región en la que el ser y el ya-noser de la cosa son uno. Pero su frontera no es sólo espacial, sino también temporal [...] la muerte está ligada a la vida de antemano y desde el interior [no] morimos en nuestro último instante.

La significación configuradora de la muerte, dirá,

delimita, esto es, conforma nuestra vida no sólo en la hora de la muerte, sino que es un momento formal de nuestra vida que tiñe todos sus contenidos: la posibilidad de delimitar de la totalidad de la vida por la muerte preactúa sobre todos sus contenidos e instantes; la cualidad y forma de cada uno serían distintas si pudieran sobrepasar esta frontera inmanente.

Ha recordado Bodei (1986: 62) que eternidad, aion en griego, aevum en latín, significa originariamente culmen o flor de la edad. Haciendo uso de la figura retórica del quiasmo, así lo traduce Simmel: "días turgentes, desbordantes, en los cuales se cree esperar todavía cualquier pasado, recordar ya cualquier alegría futura", refiriéndose al paisaje de Böcklin en el que

todo es como en los instantes del mediodía estival, cuando la naturaleza contiene la respiración, cuando el curso del tiempo se coagula. La esfera en la cual ahora sentimos no es la eternidad en el sentido de la duración inmensa, por consiguiente no es la eternidad en el sentido religioso, es simplemente el cesar de las relaciones temporales. Al mismo tiempo llamamos eterna a una ley na- tural no porque exista desde siempre, sino porque su validez no tiene absolutamente nada que ver con el antes ni con el después. (Simmel 1985: 86)

Como ha insistido Bodei (1986: 66-67), relacionándolo con la idea goethiana de metamorfosis -el conservarse de la forma a través de las mutaciones-, "cada momento en apariencia casual y amorfo contiene en sí en potencia la génesis y la desaparición de una determinada forma".

Cuenta Lukács" que Simmel, en cierta ocasión, habría dicho "había demasiado pocas categorías como había demasiado pocos sexos". Sin embargo, Simmel hizo del dualismo un principio, acaso porque, como gustaba decir, "dos es más antiguo que uno". La vida como dualismo, en efecto, es el primer epígrafe a modo de paratexto de su espléndido ensayo "Filosofía de la moda" (Simmel 1923), donde subrayará las oposiciones particular/universal, igualdad/diferenciación, imitación/distinción, cohesión/separación. Dualismo que encontrará en la fisiología: "La base fisiológica de nuestro ser nos ofrece la primera indicación; necesitamos del movimiento no menos que de la quietud, de la productividad como de la receptividad", en la vida espiritual, en la afectiva

[...] la historia entera de la sociedad puede desarrollarse al hilo de las luchas y compromisos, de las conciliaciones lentamente logradas y pronto deshechas que tienen lugar entre el impulso a fundirnos con nuestro grupo social y el afán de destacar fuera de él nuestra individualidad.

Anteriormente, en Filosofia del dinero, ya había señalado que "la moda es una de esas instituciones sociales que unifican, en una proporción peculiar el interés por la diferencia y el cambio que se da por la igualdad y la coincidencia" (Simmel 1977a: 580).

En el interior de la constante contraposición que proviene del dilema vida-forma -la moda es una Lebensform, una forma de vida (vida como el movimiento y el esfuerzo por el cual nuestra conciencia busca ajustar un contenido a una forma; forma como orden plástico, modificable, vivo, una dirección y una tendencia más que una cosa)-, Simmel se refiere, como Gabriel Tarde, o como Spencer, a la propensión psíquica a la imitación, el tránsito de la vida en grupo a la vida individual. El que imita, dice, transfiere a los demás la exigencia de ser original y de la responsabilidad por su acción. El imitador que actúa porque los demás obran así se opone al hombre que obra en vista de finalidades, el hombre teleológico.

No parece que Simmel, tan cáustico con la imitación -la hija que el pensamiento tiene con la estupidez-, vea en el hombre moderno, ¿peregrino?, 
¿flanêur? siempre in itinere, a alguien con fines precisos, con objetivos certeros, con metas. Así, en su bellísimo ensayo sobre Rodin, ${ }^{5}$ de quien decía que nos libera porque traza con la más alta perfección la imagen de esa vida que se agota en la pasión del movimiento, se refiere al alma humana, "para la cual el destino universal supone [...] un punto de tránsito de una trayectoria que viene de lo indefinido, un alma amante de los caminos sin metas y de las metas sin camino" (Simmel 1988: 168).

El conflicto entre autoafirmación considerada como diferencia -autosuperación o individualismo estético- y disolución en el mundo de las formas es otra constante en la reflexión de Simmel, quien subraya que "la moda es imitación de un modelo dado", lo que satisface la necesidad de apoyarse en la sociedad librándose del tormento de decidir, transfiriendo a los demás las exigencias de ser originales, reduciendo la conducta de cada uno (token) a mero ejemplo de una regla (type). Pero "no menos satisface la necesidad de distinguirse, la tendencia a la diferenciación, a cambiar, a destacarse". Para Simmel, más que la variación de los contenidos, esto sucede sobre todo porque, asevera, siempre las modas son modas de clase. En este punto, Simmel parece concordar con Veblen: ${ }^{6}$ las modas de la clase social superior se diferencian de las de la inferior y son abandonadas en el momento en que esta comienza a acceder a ellas.

Deudor de Simmel, E. Goffman lo expresará asi: la estructura de clase de la sociedad requiere la apropiación de estratagemas simbólicas mediante las cuales las clases sociales puedan distinguirse la una de la otra. El vestido en general y la moda en particular se prestan en modo admirable a este objetivo en cuanto proporcionan un medio altamente visible, pero económicamente estratégico, con el que quien está "arriba" puede, a través de la calidad y el "estar de moda" del propio vestido, comunicar su superioridad de clase a quien está "debajo". Además, el hecho de quien está "debajo" llegue rápidamente a emular, siempre toscamente, las modas de las clases superiores testimonia simbólicamente la legitimidad de los modelos de deferencia ínsitos en un sistema de clases. En otras palabras, quien está debajo demuestra de este modo un "justo respeto" hacia los propios "superiores" (Goffman 1951: 294-304)

El concebir la moda como moda de clase dio paso a caracterizar la difusión de la moda, de las clases más altas a las más bajas, en sentido vertical, tal como lo define la trickle-down theory o Tröpfelmodel, 7 un mecanismo que permite la difusión "gota a gota" de las modas por medio de la jerarquía de los estatus. Quienes, como Blummer, ${ }^{8}$ hayan cuestionado la explicación trickle-down sustituyéndola por "selección colectiva", o quienes sostienen hoy que la difusión de la moda más que vertical es horizontal, no han conseguido, creo, superar en lo esencial el diagnóstico de Simmel.
De pasada dice Simmel que si examina la historia de las modas nos percataremos de que sólo ha sido estudiada, antes que él, en función de sus contenidos. A este respecto cabe recordar el Tratado de la vida elegante (1830) de ese gran admirador de Brummel, Balzac, para quien "el vestido es la expresión de la sociedad", en el que se sostiene que

explicar la larga cabellera de los francos, la tonsura de los monjes, los cabellos rasurados de los siervos de la gleba, las pelucas de Popocambou, los coloretes de los aristócratas y los titus de 1790 equivale a contar las principales revoluciones de Francia. Del mismo modo que preguntar por el origen de los zapatos à la poulaine, de los bolsos, de las capuchas, de las escarapelas, de las canastas, de los guantes, de las máscaras, del terciopelo es generar un modilogue en el pavoroso dédalo de las leyes suntuarias.

Simmel, en cambio, propone estudiar su significación para la forma del proceso social que permitiría conocer la historia de los ensayos hechos para adaptar al estado de cada cultura individual y social la satisfacción de las dos opuestas tendencias, la de imitar y la de diferenciarse.

El ver la moda como producto de la división en clases le permite observarla, en su comportamiento, como similar al honor, cuya doble función consiste en trazar un círculo cerrado en torno de sí y al mismo tiempo separado de los demás. El honor, el punto de honor (pundonor), ha dicho Weinnrich, ${ }^{10}$ es una ética de la opinión pública; lo que permite relacionarlo con el pudor, la vergüenza, el miedo, sentimientos que se encuentran en el origen de la moda, o mejor del vestido, como narra el Génesis $(3,7 ; 3,10 ; 3,21)$. Simmel, al definirlo espacialmente, como hará con la envidia - "la envidia mide [...] nuestra distancia con el objeto, y esto implica cierta lejanía junto con cierta proximidad"-, relaciona a su vez el honor con el marco de un cuadro ${ }^{11}$ que da a la obra de arte el carácter de un todo unitario, orgánico, que forma un mundo para sí, y al mismo tiempo, actuando hacia fuera, relaciona todas las vinculaciones con el entorno espacial. En definitiva, una frontera que diferencia lo de adentro de lo de afuera.

El carácter abstracto y arbitrario de la moda se manifiesta en la indiferencia de la moda, en tanto forma, frente a sus contenidos. "A veces son modernas cosas tan feas y horrorosas que parece como si la moda no se propusiera sino mostrar su poder haciendo que aceptemos, en aras de ella, lo más horrible."

Podemos ratificar la sorprendente vigencia de estas consideraciones comparándolas con un texto reciente de Yuri Lotman (1999: 113): 
El cambio regular de la moda, con sus constantes epítetos "caprichosa", "voluble", "extrana", que subraya la ausencia de la motivación, la aparente arbitrariedad de su movimiento, resulta una especie de metrónomo del desarrollo cultural. El carácter acelerado del movimiento de la moda está ligado al refuerzo del papel de la iniciativa personal en el proceso dinámico. En el espacio cultural del atuendo se desarrolla una lucha constante entre la tendencia a la estabilidad, a la inmovilidad (esta tendencia es psicológicamente vivida como justificada por la tradición, por el hábito, la moralidad por consideraciones históricas y religiosas) y la orientación opuesta hacia la novedad, la extravagancia: todo esto entra en la representación de la moda. De tal manera, la moda, se vuelve casi la encarnación visible de la novedad inmotivada, lo cual permite interpretarla ya sea como dominio de caprichos monstruosos ya sea como esfera de creatividad innovadora. Un elemento obligatorio de la moda es la extravagancia. Esta última no es negada en el resurgimiento periódico de una moda orientada por la tradición, dado que la tradición misma, en este caso, resulta ser una forma extravagante de rechazo de la extravagancia. Insertar un elemento determinado en el espacio de la moda significa volverlo relevante, dotarlo de significado semírtico. La inserción en la moda es un proceso continuo de transformación de lo no significante en significante. ${ }^{12}$

No hay estudio sobre la moda que no recuerde el tan citado aforismo de Coco Chanel, "moda es lo que se pasa de moda". Mucho, mucho tiempo antes, Simmel había insistido en que a la moda lo único que le importa es sólo la variación. En Filosofía del dinero ya había señalado que si las modas de hoy [sic] ya no son tan extravagantes y costosas como las del pasado, y además tienen una menor duración, ello se debe a que se incorporan a círculos más amplios (es mucho más fácil hacer que las clases inferiores se las apropien). $\mathrm{El}$ resultado de esta transformación de la moda, tanto en su extensión como en su velocidad, es que "aparece como un movimiento autónomo, como un poder objetivo, desarrollado a través de las fuerzas propias, que hacen su cambio con independencia de la intervención de los individuos". En "Filosofía de la moda" lo dirá así: "la moda es, en su íntima esencia, sobreindividualidad".

En cuanto movimiento autónomo [sic], la moda se puede relacionar en Simmel con la aventura, ad-ventura, el moverse hacia cosas futuras, que está contenido en el presente, en el fulminante transcurrir de las experiencias. Tal es ciertamente, dice Simmel, la forma de la aventura en el sentido más general: "que se desprende del contexto de la vida".

La aventura posee principio y final en un sentido mucho más nítido de lo que acostumbramos a predicar de otras formas de nuestros contenidos vitales. Res- ponde esto a su desvinculación de los entrelazamientos y encadenamientos de aquellos contenidos, a su cambiarse en un sentido que existe para sí. Al tratarse de los acontecimientos del día y del año, nos damos cuenta de que uno de ellos ha tocado a su fin cuando o porque otro empieza; se determinan mutuamente sus límites y así, en definitiva, se configura o habla la unidad del contexto de la vida. La aventura, por el contrario, en su sentido específico, es independiente del antes y del después; sus límites se determinan sin referencia a estos.

Es, dice, en otro paso, como una isla en la vida, cuyo comienzo y final están determinados por sus propias fuerzas configuradoras y no, como en el caso de un trozo de continente, también por las de sus antecesores y sucesores (Simmel 1988: 13).

La velocidad de la moda la explica así: "cuanto más nerviosa es una época tanto más velozmente cambian sus modas (ya que uno de sus sostenes esenciales, la sed de excitantes siempre nuevos, marcha mano a mano con la depresión de las energías nerviosas)". En "Las grandes urbes y la vida del espíritu", nuestro autor sentencia que el fundamento psicológico sobre el que se alza el tipo de individualidad de la urbe es el "acrecentamiento de la vida nerviosa". Los bosquimanos, dirá, al no disponer de una articulación en clases, no manifiestan interés por la variación en los vestidos y en los adornos; los cafres, en cambio, al poseer una jerarquía social graduada con todo detalle, experimentan un cambio bastante rápido de las modas.

En el fluir incesante de momentos fugaces, con la intensificación de la vida nerviosa, ve Simmel la característica de la modernidad (cuyo étimo, modus, lo relaciona con la moda), que para Baudelaire era, como se sabe, lo transitorio, lo fugitivo, lo contingente. ${ }^{13}$

Pertenece la moda al tipo de fenómenos cuya intención estriba en lograr una expansión y una realización cada vez más completa -el signo de la moda es eficaz- pero que, con la consecución de esa finalidad absoluta, entran en contradicción consigo mismos y acaban aniquilados.

El tempo de la moda es como el de la vida moderna, impaciente, lo que indica no sólo el ansia de un rápido cambio de los contenidos cualitativos de la vida, sino también la potencia que adquiere el atractivo formal de los límites, del comienzo y del final, del llegar y del irse. Así lo dice Simmel:

la moda, con su juego entre la tendencia a una expansión universal y la aniquilación de su propio sentido que comporta justamente esa expansión, posee el atractivo singular del límite, el atractivo simultáneo del comienzo y del final, de la novedad y al mismo tiempo de la caducidad. 
Cabe recordar aquí al Benjamin de los Passagen Werke, para quien "cuanto más efímero es un tiempo, tanto más se orienta según la moda", en el que se puede detectar una gran influencia simmeliana.

Nacimiento y muerte - la primera a través de las circunstancias naturales, la segunda a través de circunstancias sociales- reducen notablemente, alli donde devengan actuales, el radio de acción de la moda. Este dato de hecho aparece en su justa luz a través de dos circunstancias. La primera se refiere a la muerte y muestra cómo la incesante creación natural de la vida es "superada y conservada" (aufgehoben) en la moda, mediante la novedad. La segunda concierne a la muerte. También esta, no menos que aquella, es "recuperada y conservada" en la moda, y precisamente mediante el sex-appeal de lo inorgánico que la moda libera. 14

La cuestión de la moda no es ser o no ser, dirá Simmel, sino que ella es simultáneamente ser y no ser, se sitúa siempre en la división de las aguas entre el pasado y el futuro, proporcionándonos así mientras está en su apogeo un sentimiento de presente tan intenso como pocos fenómenos. "Aunque la culminación en cada momento de la conciencia social en el punto que ella designa entraña también el germen de su muerte, su inevitable destino de ser sustituida, el carácter transitorio que esto implica no la descalifica en conjunto, sino más bien añade a sus atractivos uno más."

La moda parecería saber sólo conjugar el presente, un presente impaciente, un presente acentuado para Simmel. Para Barthes, en Systeme de la mode, el presente es un presente vengador que sacrifica cada temporada los signos de la temporada precedente.

Por una parte, el hoy de la Moda es puro, destruye todo a su alrededor, desmiente el pasado con violencia, censura el advenir, desde el momento en que este advenir excede la estación; y por otra parte cada uno de estos hoy es una estructura triunfante, cuyo orden es extensivo (o extraño) al tiempo, de suerte que la Moda proporciona lo nuevo incluso antes de producirlo y realiza esa paradoja de un nuevo, imprevisible y sin embargo regulado; [...] cada Moda es a la vez inexplicable y regular. Así la memoria lejana abolida, el tiempo reducido al dualismo de lo que es demolido y de lo que es inaugurado, la Moda pura, la Moda lógica no es jamás otra cosa que una sustitución amnésica del presente al pasado. ${ }^{15}$

El presente de la moda con vocación de eternidad lleva a decir a Simmel que "tiene la moda la propiedad de que cada nueva moda se presenta con aire de cosa que va a ser eterna", lo que no contradice su principio fundamental: a la moda ciertamente lo que le importa es variar.

En sus consideraciones topológicas y espaciales habla de la moda que viene de afuera, cuyo origen exótico, dice, parece favorecer la concentración del círculo que la adopta. Precisamente por venir de afuera, engendra esa forma de socialización tan peculiar y extraña que consiste en la referencia común de los individuos a un punto situado fuera de ellos. Idea esta que se halla presente en su digresión sobre el Extranjero, que no es el que viene hoy y se va mañana, sino el que viene hoy y se queda mañana. ${ }^{16}$

uga unión entre la proximidad y el alejamiento contenida en todas las relaciones humanas, dice en "El Extranjero", ha tomado aquí una forma que podría sintetizarse de este modo: la distancia dentro de la relación significa que el próximo está lejano, pero el ser extranjero significa que el lejano está próximo. Idea esta que trasladó al campo de las emociones; por ejemplo, la envidia: "De lo que se envidia se está al mismo tiempo más cerca y más lejos del bien cuya no posesión no es indiferente"; la envidia vista de esta manera permite medir, por decirlo así, la distancia con el objeto, lo que siempre supone lejanía y proximidad.

No importa el espacio, puesto que es "una forma que en sí misma no produce efecto alguno" -aunque, como dijo Kant, es "la posibilidad de la coexistencia" - sino el confín, el límite, la frontera, que como en matemática se puede definir como un conjunto de puntos que pertenecen simultáneamente al espacio interior y al espacio exterior. ${ }^{17}$ En palabras de Simmel, el límite no es un hecho espacial con efectos sociológicos, sino un hecho sociológico con una forma espacial. Acaso por ello haya reparado en el doble sentido que posee la preposición "entre": la relación entre dos elementos (que en sustancia no es más que un solo movimiento que se verifica en uno y en otro, de un modo inmanente) tiene lugar entre ellos, en el sentido espacial (Simmel 1977b: 645).

Si se habla de movimientos cíclicos, aparece otra analogía simmeliana, la que relaciona el ritmo con la simetría: "El ritmo en el tiempo es análogo a la simetría en el espacio y transmite una idea de orden que garantiza un elevado grado de previsibilidad de los comportamientos".

No se le escapó a Simmel, con mirada de entomólogo, el comportamiento de lo que hoy se denominaría fashion victim, que él indistintamente llama esclavo o frenético de la moda, y de su simétrico demodé o el hostil a la moda:

Si ir a la moda es imitación del ejemplo social, ir deliberadamente demodé es imitar lo mismo pero con signo inverso. No es, pues, la hostilidad a la moda menor testimonio del poder que sobre nosotros ejerce la tendencia social [...] 
la antimoda preconcebida se comporta ante las cosas lo mismo que el frenético de la moda, sólo que rigiéndose por otra categoría: mientras este exagera cada elemento, aquella lo niega. Hasta puede ocurrir que en círculos enteros, dentro de una amplia sociedad, llegue a ser moda el ir contra la moda.

Y esto lo dijo nuestro autor mucho antes de la aparición de la moda de los blue jeans.

Bajo el epígrafe "La tragedia de la moda", Simmel se ocupa de ubicar la moda dentro del tipo de fenómenos cuya intención es extenderse ilimitadamente, lograr una realización cada vez más completa, pero que al conseguir esta finalidad absoluta caerían en contradicción consigo mismos y quedarían aniquilados. La moda, apenas alcanza su objetivo, muere en cuanto moda "víctima de la contradicción lógica consigo misma, porque su expansión total suprime en ella la fuerza eliminatoria y diferencial". La moda, hermana de la muerte, diría Leopardi, son ambas hijas de la Caducidad. König (1972) lo expresará asi: "Hay como un deseo de suicidio que roe a la moda y que se realiza en el momento que alcanza su apogeo".

A la moda, insiste Simmel, lo que le importa es variar, pero, añade, como en todo lo demás del mundo, existe en ella una tendencia a economizar esfuerzo; trata de lograr sus fines lo más ampliamente posible, pero, a la vez, con los medios más escasos que sea dado; de suerte que ha podido compararse su ruta con un círculo. Por este motivo, recae siempre en formas anteriores, cosa bien clara en las modas del vestir. Con gran lucidez afirma: apenas una moda pasada se ha borrado de la memoria, no hay razón para no rehabilitarla. La que la ha seguido atraía por su contraste con ella; al ser olvidada, permite renovar este placer de contraste oponiéndola a su vez a la que por la misma causa le fue preferida.

El atractivo especialmente picante y seductor de la moda reside, según nuestro autor, en el contraste que se establece entre su difusión tan extensa y omniabarcadora y una rápida y radical transitoriedad, en el derecho reconocido a la infidelidad para con ella.

Veamos ahora cómo esta idea de la recuperación de una moda pasada ya olvidada es expresada, bien que con tintes benjaminianos, por Baudrillard (1977: 132): la moda, el juego más superficial, la forma social más profunda, "extrae frivolidad de la muerte que nada dura, y el placer inverso de saber que más allá de esa muerte, toda forma tiene siempre la oportunidad de una segunda existencia”. Si la modernidad es un código, afirmaba Baudrillard, la moda es su emblema. ${ }^{17}$

Ya hemos mencionado el étimo modus, sea de moda o de modernidad. Nos ha recordado Eco (1995) cómo también la moderación significa estar dentro del modus, o lo que es lo mismo, una cierta medida, dentro de ciertos límites. La palabra modus nos recuerda, siempre según Eco, dos reglas que hemos heredado de la civilización griega y latina: el principio lógico del modus ponens y el principio ético formulado por Horacio: est modus in rebus sunt certi denique fines, quos ultra citraque nequit consitere rectum (hay una medida en todas las cosas, hay en suma confines precisos/más allá de los cuales no puede existir lo recto). Así, el infinito, apeiron, sería lo que no tiene el modus. $^{18}$

En Diario póstumo, Simmel escribe:

El proceder del mundo me parece como el moverse de una rueda monstruosa justamente como el presupuesto del eterno retorno. Pero de todos modos no con la misma consecuencia, realmente en algún momento se repite lo idéntico. La rueda en efecto tiene un radio infinitamente grande. Sólo cuando ha transcurrido un tiempo infinito, es decir jamás, lo idéntico puede volver al idéntico lugar.

La moda puede, aparentemente y en abstracto, acoger cualquier contenido. Cualquier forma de la indumentaria, del arte, de los comportamientos o de las opiniones puede ponerse de moda. $Y$ sin embargo, dice nuestro autor, en la esencia íntima de algunas formas late una disposición singular para desarrollarse como moda, mientras que otras se resisten a ello también desde su interioridad. Pone Simmel como ejemplo todo lo que puede denominarse "clásico", relativamente lejano y ajeno a la forma de la moda. La esencia de lo clásico, dice, es una concentración de los fenómenos en torno de un centro inmóvil. El clasicismo tiene siempre algo de recogimiento en sí mismo y ofrece muy pocos puntos débiles en los que puedan hacer mella la modificación, la ruptura del equilibrio, la destrucción. Es característica de la escultura clásica la contención de los miembros. El conjunto es dominado de manera absoluta desde la interioridad; el espíritu y el instinto vital del todo mantienen uniformemente bajo su poder a cada fragmento del mismo a través de la perceptible contención de su apariencia exterior. Esta es la razón de que se hable de la "calma clásica" del arte griego. Se debe exclusivamente a la concentración de la forma exterior, que no permite que ninguna parte de ella entre en relación con fuerzas y destinos exteriores, despertando de este modo la sensación de que la configuración en cuestión se sitúa al margen de las cambiantes influencias de la vida general. Para ser moda, dice, lo clásico debe mutar en clasicismo y lo arcaico en arcaísmo. A modo de contraste, todo lo barroco, desmesurado y extremo es íntimamente proclive a la moda. Dice Simmel: los miembros ampliamente dispersos de la estatua barroca están siempre como en peligro de quebrarse. La vida interior de la figura no los domina ple- 
namente, sino que los abandona a lo que dictaminen los azares de la realidad externa. Las creaciones barrocas, o al menos muchas de ellas, llevan la impronta de la inquietud, del influjo de lo casual, de la sumisión al impulso momentáneo que la moda realiza como forma de la vida social. No creo que puedan describirse mejor estos contrastes en función, cómo no, de los límites, una de cuyas características es la movilidad que permitio, por ejemplo, durante el barroco, como ha señalado Lotman (1999: 101), que sobre el fondo de una tradición ya constituida se incluyera el pedestal en una roca, ligándolo de manera temática en una única composición con la figura. 19

Como en la Moda, en este caso se puede hablar de delimitación ( $A b$ grenzung), del atractivo formal del límite, del conjuntarse el continuum de la vida y el discontinutum de las formas, del modo en que "el contenido de la representación no coincide con la representación del contenido". Como en la moda, el confin es el lugar del contraste; es la cosa misma y al mismo tiempo el cesar de la cosa, el territorio circunscripto en que el ser y el ya-no-ser de la cosa es una sola cosa. Como la Moda, o la Forma Moda, la Forma es antítesis de la continuidad. Como el juego, como la coquetería, como la seducción, como la ad-ventura. O como dijo de sí mismo en una carta que escribib a Marianne Weber en 1912

Ahora giro las velas y busco una tierra todavia no pisada. El viaje podrá incluso concluir antes de alcanzar la costa. Al menos no me sucederá como a muchos de mis compañeros, que se encuentran tan cómodos en su nave que llegan a pensar que la nave misma sea la tierra buscada. (Citado en A. Cavalli 1993: 83.)

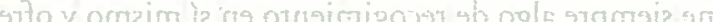

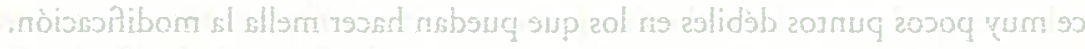

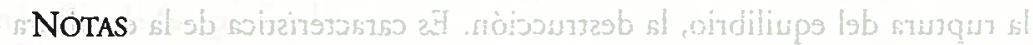
1. Carta de Theodor W. Adorno a Walter Benjamin, del 10 de noviembre de 1938 , en Benjamin (1978: 364). La respuesta de Benjamin se encuentra en la carta que le escribió a Adorno desde París el 6 de agosto de 1939, donde le comenta Filosofta del dinero y cuánto le impresionó la crítica de la teorfa del valor de Marx (1978: 383 384). En Benjamin (1986, 121-122), en la parte dedicada a la moda, cita en varias ocasiones a Simmel.

2. El capítulo 11 se titula justamente "Georg Simmel. La modernidad como eterno presente". Entre 1897 y 1907, Simmel publicó varios textos breves en la revista de Munich Jugend, de donde el movimiento Jugendstil. Una parte de ellos apareció bajo el título "Momentbilder sub specie aternitatis". Algunas Instantáneas sub specie aternitatis fueron publicadas en Aut-Aut, ne 257, 15-19, 1993.

3. A. Cavalli (1993: 73-85). Refiriéndose al Lebenstempo cita a Simmel: "Lo que llamamos tiempo de la vida es el producto del número y de la profundidad de los cambios" (p. 82).

4. A los pocos días de la muerte de Simmel (1918), el joven Luckács escribió un breve texto, "Georg Simmel”, a quien califica como el más grande filósofo del impresionismo: "[...] era un Monet de la filosoffa, a quien hasta ahora no ha seguido todavía ningún Cézanne" (Peruchi 1998: 67-76).

5. Simmel (1988: 168). Considera Simmel a Rodin como el primero en descubrir la intemporalidad artística del movimiento puro.

6. Thorstein Veblen (1974, original 1899), sobre todo el capítulo VII: "El vestido como expresión de la cultura pecuniaria”. En p. 177 se lee: “los vestidos elegantes cumplen su finalidad de ser elegantes no sólo por el hecho de que sean costosos, sino también porque son los emblemas del bienestar. No sólo demuestran que quien los lleva es capaz de gastar una cantidad de dinero relativamente grande, sino que al mismo tiempo ponen de manifiesto que consumen sin producir". En p. 183, Veblen dice: "se considera bella la moda dominante", aserto que compartirá Simmel. 7. Veblen, como Simmel, sostuvieron que la nueva moda pertenecía a las clases sociales superiores, se ha querido ver en ellos una confirmación de la difusión "gota a gota". Sobre la trickle-down theory se pueden consultar B. Barber (1957), Social Stratification, Nueva York, Hancourt, o D. E. Robinson (1961), "The Economics of Fashion Demand", Quarterly Journal of Economics, LXXV, $n^{2}$ 3. El término Tröpfelmodel (modelo "gota a gota") es empleado por el sociólogo G. Wiswide, en "Theorien der Mode aus soziologischer Sicht", Jahrbuch der Absatz und Verbanchs Forshuny, 1, 1971, p. 87, en N. Squicciarino (1986: 164).

8. H. Blummer desarrolló la entrada "Fashion" en la International Encyclopaedia of the Social Science. En un artículo del Sociological Quarterly X (1969), Summer escribió: "El mecanismo de la moda no parece derivar de una necesidad de diferenciación o emulación de clase, sino del deseo de estar a la moda, de estar a la altura de lo que es apreciado y considerado bello, de expresar los nuevos gustos que emergen en un mundo en continuo cambio". Sobre la teoría de la selección colectiva de Blummer, véase Fred Davis, Fashion Culture and Identity, University of Chicago.

9. Idea esta que se encuentra en el clásico Influencia personal, de E. Kantz y P. F. Lazarsfeld. Más recientemente, C. W. King "Fashion Adaption: A Resultal to the 'Trickie Down' Teory', en G. B. Sproles (ed.), Perspectives of Fashion, Minneapolis, Burgges, 1981. Asimismo, Squicciarino (1986) y Davis (1992).

10. H. Weinnrich, “Mitologia dell'onore”, en Weinnrich (1976: 221). Alli dice: "puesto que el honor consiste en la opinión de los otros sobre el propio valor, puede perderse por medio de los otros". De ahí la necesidad de "lavar la vergüenza". Simmel, en "Filosoffa de la moda", dirá que el sentimiento de vergüenza nace cuando el individuo se sabe destacado en un conjunto. En "El secreto y la sociedad secreta" dice Simmel: "El honor traza una de estas fronteras en derredor del hombre 
y, con mucha finura, caracteriza el idioma las ofensas al honor con la frase acercarse demasiado". Simmel (1977b: 369).

11. No creo exagerar si encuentro inspiración simmeliana en el texto que Ortega escribió en abril de 1921, Meditación del marco. En 1923, en el primer número de Revista de Occidente, apareció "Filosofia de la moda" y, posteriormente, hizo publicar "El asa". Menos exagerado aún es encontrar igualmente inspiración simmeliana en el fundamental Frame Analysis de E. Goffman.

12. Véanse Y. Lotman, Moda Abbligliamento (Lotman 1994) y prólogo J. Lozano (Lotman 1999). Asimismo U. Volli (1988).

13. En "La modernite", Le Peintre de la Vie Moderne, Baudelaire (1986). La cita exacta es "la modernité c'est le transitoire, le fugitif, le contigent, la moitié de l'art, dont l'autre moitic est l'eternel et l'immuable" (p. 467). En "Eloge du maquillage" (p. 492), dirá "Toutes les modes sont charmantes".

14. Benjamin (1977: 124). Esta cita dio pie a Mario Perniola, que define la moda como "estrategia de las apariencias", a titular un libro suyo $E l$ "sex-appeal" de lo inorgánico, Madrid: Trama, 1998. Idea que aparece también en Disgusti, Milán: Costa Nolan, 1999.

15. Systeme de la mode, en R. Barthes (1994: 366-367); en nota dice Barthes: "De hecho, la moda postula una ucronfa, un tiempo que no existe; el pasado es vergonzoso y el presente 'comido' sin cesar por la Moda que se anuncia”.

16. "Digresión sobre el Extranjero", incluida en "El Espacio y la Sociedad" (1977b: 716). En "Filosoffa de la moda", Simmel dedica una parte a la moda y lo extranjero subrayando la gran predilección por importar la moda del extranjero: "Precisamente por venir de afuera, engendra esa forma de socialización tan peculiar y extraña, que consiste en la referencia común de los individuos a un punto situado fuera de ellos". 17. "La Mode ou la Férie du Code", en Baudrillard (1977: 132): "La moda es siempre retro, pero sobre la base de la abolición del pasado: muerte y resurrección espectral de las formas. Su actualidad propia no guarda referencia al presente, sino reciclaje total e inmediato; la moda es paradójicamente inactual. Supone siempre un tiempo muerto de las formas, una especie de abstracción por la que se deriven signos eficaces [...] Esthétique du recommecement [...]".

18. Recuerda Eco la obsesión latina por los límites, comenzando por la fundación de Roma (Rómulo traza una línea de conffn y mata al hermano porque no la ha respetado); posteriormente la ideología de la Pax Romana y el proyecto político de César Augusto se basan sobre una definición precisa de los confines; cuando Julio César pasa el Rubicón exclama "Alea jacta est". Simmel (1986: 31) escribió en su ensayo "Puente y Puerta": "Es esencial para el hombre, en lo más profundo, el hecho de que él mismo se ponga una frontera, pero con libertad, esto es, de modo que también pueda superar esta frontera, situarse más allá de ella" y "el hombre es el ser fronterizo que no tiene ninguna frontera".
19. El ejemplo que proporciona es la roca sobre la cual Falconet situó su estatua de Pedro el Grande en San Petesburgo. "Paolo Trubeckoi situó al proyectar el monumento a Alejandro III, introduce en él una cita escultórea de la obra de Falconet: el caballo puesto sobre una roca. La cita tenía, sin embargo, un sentido polémico: la roca que bajo los zócalos de Pedro confería a la estatua un empuje adelante. En Trubeckoi se transformaba en barranco y abismo. Su caballero había cabalgado hasta el límite y se había detenido pesadamente sobre el precipicio."

\section{REFERENCIAS BIBLIOGRAFICAS}

Barthes, R. (1994) Oeuvres Completes, II. París: Seuil. Baudelaire, Ch. (1986) Curiosités Esthetiques. París: Garnier. BAUDRILIARD, J. (1977) L'Echange Symbolique et la mort. Paris: Gallimard. BENJAMin, W. (1977) Lettere 1913-1940. Milán: Einaudi.

BODEI, R. (1986) "Tempi e mondi possibili. Arte avventura, straniero in Georg Simmel", Aut-Aut, 257.

Cavalli, A. (1933) "La categoria del tempo in Simmel: una lettura sociologica", Aut-Aut, 257.

DAVIs, F. (1992) Fashion, Culture and Identity. Chicago: University of Chicago.

ECO, U. (1995) Interpretazione e soprainterpretazione. Milán: Bompiani.

Frisby, D. (1985) Fragments of Modernity. Theories of Modernity in the Work of Simmel, Kracaner, and Benjamin. Cambridge: Polity Press.

GOFFMAN, E. (1951) "Symbols of Status", British Journal of Sociology II.

KÖIG, R. (1972) Sociologia de la Moda. Barcelona: Redondo. Lotman, Y. (1994) Cercare la Strada. Venecia: Marsilio. - (1999) Cultura y explosión. Barcelona: Gedisa. OrTegA, J. (1923) "Meditación del marco" en Obras Completas. Madrid: Alianza. Perniola, M. (1998) El "sex-appeal" de lo inorgánico. Madrid: Trama. __ (1999) Disgusti. Milán: Costa \& Nolan.

PERUCCHI, L. (1998) Georg Simmel La moda. Milán: Mondadori. SIMMEL, G. (1923) "Filosoffa de la moda", Revista de Occidente, 1 y 2. - (1977a) Filosofla del dinero. Madrid: Instituto de Estudios Políticos. _ (1977b) Sociologta. Madrid: Revista de Occidente. _ (1985) Il volto e il ritratto. Bolonia: Il Mulino.

- (1986) El individuo y la libertad. Barcelona: Península. - (1988) Sobre la aventura. Barcelona: Península. SQuicCIARINo, N. (1986) El vestido habla. Madrid: Cátedra. VEBLEN, T. (1974) Teorla de la clase ociosa. México: FCE. Volu, U. (1988) Contro la moda. Milán: Feltrinelli. WeinNrich, H. (1976) Metafora e Menzogna. Bolonia: Il Mulino. 